\title{
Stability and capping of magnetite ultra-thin films.
}

\author{
K. Fleischer, ${ }^{\text {a) }}$ O. Mauit, and I.V. Shvets \\ Centre for Research on Adaptive Nanostructures and Nanodevices (CRANN) \\ and School of Physics, Trinity College Dublin, Dublin 2, Ireland
}

(Dated: 13 May 2014)

Ultrathin films of $\mathrm{Fe}_{3} \mathrm{O}_{4}$ have been grown epitaxially on nearly lattice matched $\mathrm{MgO}(001)$. The stability of $4 \mathrm{~nm}$ thick films in ambient air and under annealing in an oxygen atmosphere at $200^{\circ} \mathrm{C}$ has been studied. By magneto optical and Raman measurements we can confirm the presence of the $\mathrm{Fe}_{3} \mathrm{O}_{4}$ phase and the formation of a maghemite top layer passivating the $\mathrm{Fe}_{3} \mathrm{O}_{4}$ thin film. In a second step we are able to demonstrate that this top layer oxidation in ambient air can be prevented by a $2 \mathrm{~nm}$ thick magnesium ferrite passivation layer, while a thicker $20 \mathrm{~nm} \mathrm{MgO}$ layer prevents oxidation even at elevated temperatures.

Magnetite is a material used for its ferromagnetic properties in magnetic data storage ${ }^{1}$ and ferrofluids. ${ }^{2}$ Its basic electrical, optical and crystallographic properties at room temperature are well characterised. ${ }^{3-12}$ For applications of magnetite, in-plane devices with controlled stoichiometry and crystallinity are typically required. ${ }^{13-15}$ The control over the magnetite properties in thin film form, and reliable measurements of thin film properties are complicated due to top layer oxidation of the films upon air exposure. While $\mathrm{Fe}_{3} \mathrm{O}_{4}$ is stable at room temperature, the top layers of thin film samples can be further oxidized forming maghemite $\left(\gamma-\mathrm{Fe}_{2} \mathrm{O}_{3}\right) .{ }^{16,17}$ Therefore, understanding the issues of oxidation of ultra thin films of magnetite and finding ways of preserving the film stoichiometry under ambient air is important.

This oxidation of ultra-thin magnetite layers grown on nearly lattice matched $\mathrm{MgO}(001)$ by plasma assisted molecular beam epitaxy (MBE, Model: DCA MBE M600) is investigated here. $\mathrm{Fe}_{3} \mathrm{O}_{4}$ is grown at $520 \mathrm{~K}$ by e-beam evaporation of iron. Protective layers of $\mathrm{MgFe}_{2} \mathrm{O}_{4}$ are grown at $520 \mathrm{~K}$ by e-beam co-evaporation of metallic iron and ceramic $\mathrm{MgO}$. $\mathrm{MgO}$ capping layers were grown at room temperature. Reactive oxygen was supplied by an electron cyclotron resonance plasma source (Oxford Scientific OSPrey) operating at $30 \mathrm{~mA}$ in $3 \times 10^{-6}$ mbar oxygen partial pressure.

Due to a strong dependency of thin film $\mathrm{Fe}_{3} \mathrm{O}_{4}$ properties on film thickness ${ }^{17-20}$ it is crucial to compare the effect of different capping layers on identical $\mathrm{Fe}_{3} \mathrm{O}_{4}$ films. For this reason a single $\mathrm{Fe}_{3} \mathrm{O}_{4}$ layer was grown first, which was subsequently covered by $\mathrm{MgFe}_{2} \mathrm{O}_{4}$ and $\mathrm{MgO}$ using shadow masks. This resulted in samples with the same original $\mathrm{Fe}_{3} \mathrm{O}_{4}$ layer and 4 patches: (a) Uncovered $4 \mathrm{~nm}$ thick $\mathrm{Fe}_{3} \mathrm{O}_{4}$, the same film capped by (b) $2 \mathrm{~nm}$ $\mathrm{MgFe}_{2} \mathrm{O}_{4}$, (c) $20 \mathrm{~nm} \mathrm{MgO}$, and (d) $2 \mathrm{~nm} \mathrm{MgFe}_{2} \mathrm{O}_{4}$ and $20 \mathrm{~nm} \mathrm{MgO}$. Reference samples of $20 \mathrm{~nm} \mathrm{MgO}$ and $2 \mathrm{~nm}$ $\mathrm{MgFe}_{2} \mathrm{O}_{4}$ were also produced to exclude the possibility that a magneto-optical Kerr effect (MOKE) or Raman signals originate from these layers.

To assess the crystallographic phase and the amount of surface oxidation, Raman spectra of the samples have

a)Electronic mail: fleisck@tcd.ie

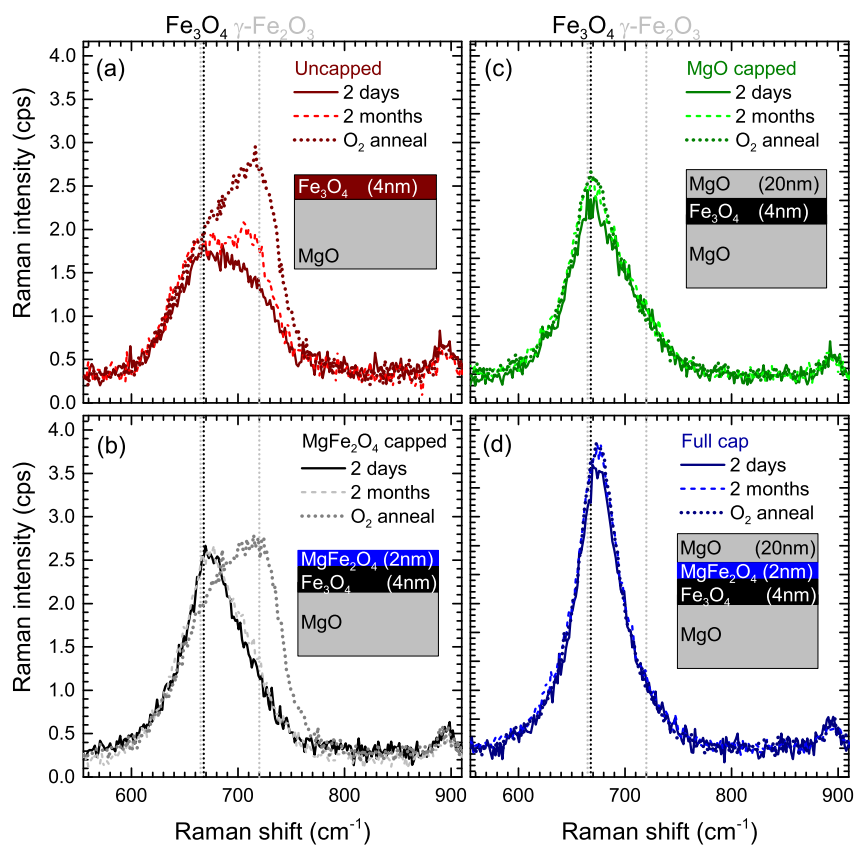

FIG. 1. Raman spectra of a differently capped $\mathrm{Fe}_{3} \mathrm{O}_{4} 4 \mathrm{~nm}$ thin film on $\mathrm{MgO}(001)$. Measurements were taken after two days of air exposure (solid lines), after 2 months of air exposure (dashed) after annealing for $20 \mathrm{~min}$ in oxygen (dotted) at $200^{\circ} \mathrm{C}$. (a) shows data for the uncapped $\mathrm{Fe}_{3} \mathrm{O}_{4}$, (b) the same film capped by $2 \mathrm{~nm} \mathrm{MgFe}_{2} \mathrm{O}_{4}$, (c) $20 \mathrm{~nm} \mathrm{MgO}$, and (d) $2 \mathrm{~nm}$ $\mathrm{MgFe}_{2} \mathrm{O}_{4}$ and $20 \mathrm{~nm} \mathrm{MgO}$.

been measured with the $488 \mathrm{~nm}$ Ar-line in a Renishaw inVia micro Raman system using $z\left(x_{001}, x_{001}\right) \bar{z}$ scattering geometry and polarisation. Magnetite can be identified by its characteristic $A_{1 \mathrm{~g}}$ mode at $665 \mathrm{~cm}^{-1}$, which shifts to higher wavenumber in thin film form due to the presence of substrate induced strain or anti phase boundaries ${ }^{21,22}$. The surface oxidized phase, which we could identify as $\gamma-\mathrm{Fe}_{2} \mathrm{O}_{3}$, has a split peak of the same symmetry, where the larger component is found at $720 \mathrm{~cm}^{-1} \cdot{ }^{16,22}$ The differently capped structures have been measured within 2 days of initial exposure to ambient air as well as subsequently in the following 2 months. As shown in Fig. 1, the uncapped samples already show a broader initial $\mathrm{Fe}_{3} \mathrm{O}_{4} A_{1 g}$ mode compared to any of the capped structures, and within the first two months 
TABLE I. Results of the peak fit of the $A_{1 g}$ mode and estimation of the over layer oxidation based on a shape analysis of the mode. For the fully capped samples, peaks were fully symmetric Lorentzian shaped and only a single peak has been fitted. For all other layers, a double peak structure was used with a shared Lorentzian width. The intensity ratio between the peaks at higher and lower energy $\left(I_{2} / I_{1}\right)$, and line broadening $(\Gamma)$ are also given. The peak ratio can be used to estimate the thickness of the $\gamma-\mathrm{Fe}_{2} \mathrm{O}_{3}$ top layer.

\begin{tabular}{lcccc} 
Sample & $\begin{array}{c}A_{1 g} \\
\left(\mathrm{~cm}^{-1}\right)\end{array}$ & $I_{2} / I_{1}$ & $\begin{array}{c}\Gamma \\
\left(\mathrm{cm}^{-1}\right)\end{array}$ & $\begin{array}{c}d_{\gamma-\mathrm{Fe}_{2} \mathrm{O}_{3}} \\
(\mathrm{~nm})\end{array}$ \\
\hline \hline $4 \mathrm{~nm} \mathrm{Fe}_{3} \mathrm{O}_{4}$ uncapped & 666,708 & 0.8 & 49 & 1.3 \\
after 2 months & 661,708 & 1.2 & 56 & 2.2 \\
after $\mathrm{O}_{2}$ anneal & 667,713 & 1.9 & 57 & 4 \\
\hline with $\mathrm{MgFe}_{2} \mathrm{O}_{4}$ cap & 672,704 & 0.2 & 50 & - \\
after 2 months & 670,704 & 0.4 & 53 & 0.4 \\
after $\mathrm{O}_{2}$ anneal & 673,716 & 1.4 & 48 & 2.7 \\
\hline with $\mathrm{MgO}$ cap $_{\text {after } 2 \text { months }}$ & 668,704 & 0.3 & 45 & - \\
after $\mathrm{O}_{2}$ anneal & 669,709 & 0.2 & 57 & - \\
\hline with full cap & 670,705 & 0.2 & 48 & - \\
after 2 months & 675 & 0 & 48 & - \\
after $\mathrm{O}_{2}$ anneal & 675 & 0 & 51 & - \\
\hline $50 \mathrm{~nm}$ thick Fe $\mathrm{O}_{4}$ & 665 & 0 & 42 & -
\end{tabular}

the shoulder at the $\gamma-\mathrm{Fe}_{2} \mathrm{O}_{3}$ peak position is becoming more pronounced. As it is known that annealing of $\mathrm{Fe}_{3} \mathrm{O}_{4}$ in oxygen atmosphere produces $\gamma-\mathrm{Fe}_{2} \mathrm{O}_{3}{ }^{16}$, the sample was exposed to a 1 bar oxygen atmosphere at $200^{\circ}$ Cfor $20 \mathrm{~min}$. This accelerated oxidation allows us to assess the long term stability of the individual capping layers more quickly. As expected the uncapped sample is completely oxidized and the measured Raman spectra is equivalent to those published for thicker $\gamma-\mathrm{Fe}_{2} \mathrm{O}_{3}$ layers. The ultra-thin $\mathrm{MgFe}_{2} \mathrm{O}_{4}$ cap was effective for extended exposures in ambient air, but did not prevent the surface oxidation upon oxygen annealing. In contrast films with the thicker $\mathrm{MgO}$ capping layer are stable even during the oxygen annealing. No significant differences in the Raman spectra were observed in this case. One interesting aspect of our study is that the combination of the $2 \mathrm{~nm} \mathrm{MgFe}_{2} \mathrm{O}_{4}$ and $20 \mathrm{~nm} \mathrm{MgO}$ was shown to result in the best $\mathrm{Fe}_{3} \mathrm{O}_{4}$ layer qualities with the sharpest $A_{1 g}$ mode. The mode width is related to the crystalline quality, strain, and the number of anti phase boundaries. ${ }^{21}$ The exact mechanism, how the structure of the top layer can affect these properties in the underlying $\mathrm{Fe}_{3} \mathrm{O}_{4}$ is not yet understood. Table I compares the $A_{1 g}$ peak analysis for all films and an estimation of the $\gamma-\mathrm{Fe}_{2} \mathrm{O}_{3}$ surface layer thickness. The latter estimation assumes that the Raman signals measured for the capped structures are equivalent to $100 \% \mathrm{Fe}_{3} \mathrm{O}_{4}\left(I_{2} / I_{1}<0.3\right)$, while the one for the uncapped sample after $\mathrm{O}_{2}$ annealing is equivalent to $100 \% \gamma-\mathrm{Fe}_{2} \mathrm{O}_{3}\left(I_{2} / I_{1}=1.9\right)$. Raman spectra of samples capped with $\mathrm{MgO}$ and $\mathrm{MgFe}_{2} \mathrm{O}_{4}$ do show a small asymmetry, which is not substantially changed by exposure to air. Such an asymmetry could arise from strain gradients within the film caused by the presence of the amorphous $\mathrm{MgO}$ top layer in case of the $\mathrm{MgO}$ cap. Similarly the 2nm thin $\mathrm{MgFe}_{2} \mathrm{O}_{4}$ cap alone could be already distorted by similar oxidation in ambient air. In case of the double cap, the lattice matched $\mathrm{MgFe}_{2} \mathrm{O}_{4}$ cap, which then itself is protected by the $\mathrm{MgO}$ could lead to an effective buffer layer relieving this strain from the thin film. For the estimation of the $\gamma-\mathrm{Fe}_{2} \mathrm{O}_{3}$ surface layer thickness we utilise the intensity ratio of a fit using to Lorentzian shaped peaks. We assume that the presence of a small component at $705 \mathrm{~cm}^{-1}$ with an intensity ratio below $0.3 \mathrm{com}-$ pared to the main peak around $670 \mathrm{~cm}^{-1}$ still describes a $\mathrm{Fe}_{3} \mathrm{O}_{4}$ only film. The ratio of $I_{2} / I_{1}=1.9$ observed for the presumably fully transformed, uncapped layer after $\mathrm{O}_{2}$ annealing is taken as the signal of a $\gamma-\mathrm{Fe}_{2} \mathrm{O}_{3}$ only film. As the film thickness is well below the penetration depth of light in $\gamma-\mathrm{Fe}_{2} \mathrm{O}_{3}$ and $\mathrm{Fe}_{3} \mathrm{O}_{4}$, the Raman signal from a layered structure can be described as a simple linear combination of the signals generated in the two materials. The peak ratio can then be used to estimate the $\gamma-\mathrm{Fe}_{2} \mathrm{O}_{3}$ layer thickness with a ratio of 0.3 indicating $0 \mathrm{~nm} \gamma-\mathrm{Fe}_{2} \mathrm{O}_{3}$ and a ratio of 1.9 indicating a fully transformed $4 \mathrm{~nm} \gamma-\mathrm{Fe}_{2} \mathrm{O}_{3}$ layer.

The importance of the protection of ultra-thin $\mathrm{Fe}_{3} \mathrm{O}_{4}$ films is immediately evident. The uncapped sample already has a $\sim 1.3 \mathrm{~nm}$ thick $\gamma-\mathrm{Fe}_{2} \mathrm{O}_{3}$ formed after air exposure which increases to $\sim 2 \mathrm{~nm}$ after prolonged exposure. Any electrical or magnetic measurements on such films are already greatly affected as more than a quarter of the material is not magnetite any more.

To demonstrate this effect we measured the polar magneto optical Kerr effect (MOKE) of the thin film samples spectroscopically. Details of the spectrometer and magnet are described elsewhere. ${ }^{23}$ The MOKE spectra of thin films are dominated by a superposition of the actual magneto-optical properties of the magnetic material, the overall reflectivity of the layered stack, and the thickness of the magnetic layer. Already for a layer thickness below $100 \mathrm{~nm}$, a reduction in Kerr rotation is typically expected. ${ }^{24}$ Consequently the Kerr rotation in the ultra-thin $\mathrm{Fe}_{3} \mathrm{O}_{4}$ films will be substantially lower than

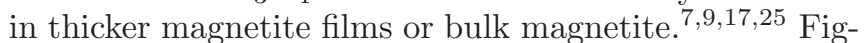
ure $2 \mathrm{a}$ compares the measured MOKE of a $50 \mathrm{~nm}$ thick film on $\mathrm{MgO}$ with the spectra of a $3 \mathrm{~nm}$ thick capped film. A simulation shows that the amplitude reduction, blue shift and broadening of the $\mathrm{Fe}_{3} \mathrm{O}_{4}$ infrared MOKE signal is qualitatively expected in an ultra-thin film. The remaining quantitative differences in the ultra-violet (UV) are caused by the presence of the $\mathrm{MgO}$ cap and a modification of the dielectric function of the $\mathrm{Fe}_{3} \mathrm{O}_{4}$ itself due to the quantum confinement effects in an ultra-thin film.

The spectroscopic MOKE measurements are not only sensitive enough to quantify the Kerr effect of just a $3 \mathrm{~nm}$ thick film, we can even observe and understand the differences introduced by the surface oxidation. Figure $2 \mathrm{~b}$ shows the changes in the MOKE spectra for the $4 \mathrm{~nm}$ uncapped samples during prolonged air exposure and after $\mathrm{O}_{2}$ annealing. Most prominently the characteristic 


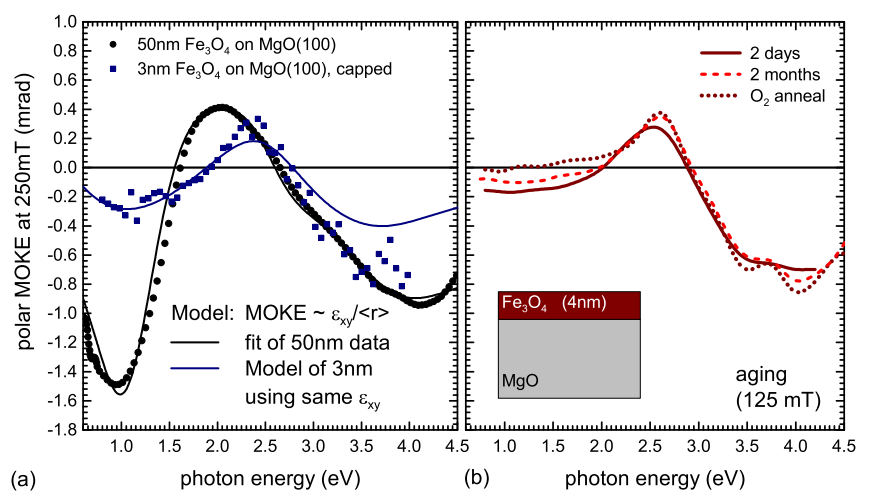

FIG. 2. a) Polar MOKE measurements of an capped $3 \mathrm{~nm}$ and uncapped $50 \mathrm{~nm}$ thick $\mathrm{Fe}_{3} \mathrm{O}_{4}$ layer on $\mathrm{MgO}(001)$ at a magnetic field of $250 \mathrm{mT}$. The optical model qualitatively describes the differences between the $3 \mathrm{~nm}$ and $50 \mathrm{~nm}$ thick sample due to the changes on overall reflection of the layer stack. b) effect of air exposure and $\mathrm{O}_{2}$ annealing on the MOKE of an uncapped $4 \mathrm{~nm}$ thick sample at $125 \mathrm{mT}$

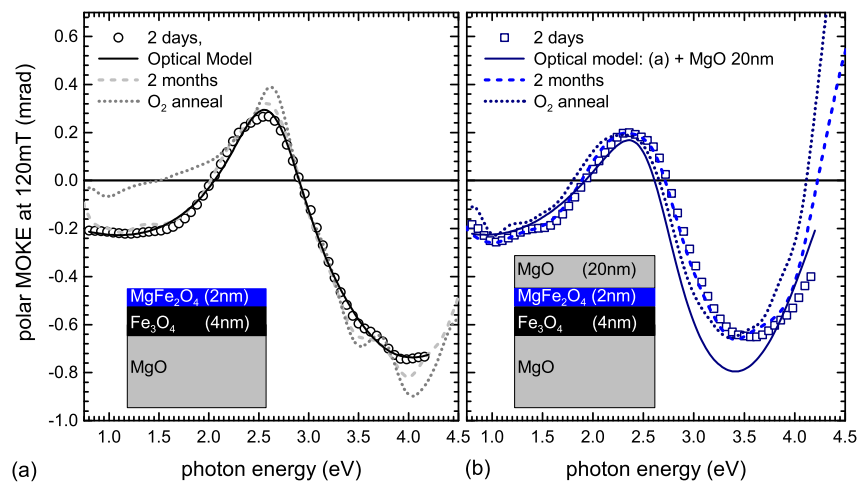

FIG. 3. MOKE spectra of $4 \mathrm{~nm}$ thick $\mathrm{Fe}_{3} \mathrm{O}_{4}$ capped with a) $2 \mathrm{~nm} \mathrm{MgFe}_{2} \mathrm{O}_{4}$ and b) a combination of $2 \mathrm{~nm} \mathrm{MgFe}_{2} \mathrm{O}_{4}$ and $20 \mathrm{~nm} \mathrm{MgO}$. Both caps maintain the MOKE signal in the infrared typically seen for $\mathrm{Fe}_{3} \mathrm{O}_{4}$. The large difference between the two types of caps is caused by interference effects in the thicker, transparent $\mathrm{MgO}$ layer as shown in the optical model.

infra-red MOKE signal of $\mathrm{Fe}_{3} \mathrm{O}_{4}$ disappears upon transformation of the layer into $\gamma-\mathrm{Fe}_{2} \mathrm{O}_{3}$. In the UV spectral range changes the MOKE also changes, characteristically by a sharpening and blue shift of the maximum to $2.6 \mathrm{eV}$ and the splitting of the broad minimum at $3.7 \mathrm{eV}$ into a doublet. All these changes are consistent with measuring a linear combination of the MOKE signal from $\mathrm{Fe}_{3} \mathrm{O}_{4}{ }^{17}$ and $\gamma-\mathrm{Fe}_{2} \mathrm{O}_{3}{ }^{26}$ with increasing $\gamma-\mathrm{Fe}_{2} \mathrm{O}_{3}$ content for aged and annealed films.

Most interesting for applications we can also confirm that the magnetic properties of the ultra-thin films are stable, once the capped layers are used. Figure 3 shows the MOKE spectra of the $\mathrm{MgFe}_{2} \mathrm{O}_{4}$ capped film and the full cap using $2 \mathrm{~nm}$ of $\mathrm{MgFe}_{2} \mathrm{O}_{4}$ and $20 \mathrm{~nm}$ of $\mathrm{MgO}$. The thin $\mathrm{MgFe}_{2} \mathrm{O}_{4}$ is already sufficient to prevent unwanted oxidation of the $\mathrm{Fe}_{3} \mathrm{O}_{4}$ in ambient air, while the full cap even protects the film in accelerated aging test using 20 min annealing in oxygen at $200^{\circ} \mathrm{C}$. The differences in the measured MOKE between the $\mathrm{MgFe}_{2} \mathrm{O}_{4}$ capped and layers capped with additional $\mathrm{MgO}$ are not caused by changes in the $\mathrm{Fe}_{3} \mathrm{O}_{4}$ properties, but by the onset of interference fringes arising from the transparent $\mathrm{MgO}$ cap. This is shown by the optical model in Fig. 3b, where we modelled the effect of a $20 \mathrm{~nm} \mathrm{MgO}$ layer on the total MOKE of the 1 day old sample shown in Fig. 3a.

In conclusion, we have demonstrated that uncapped ultra thin $\mathrm{Fe}_{3} \mathrm{O}_{4}$ layers are not stable in ambient air but are surface oxidized and transformed into $\gamma-\mathrm{Fe}_{2} \mathrm{O}_{3}$. The initial oxidation after even just 1 day of exposure to air is limited to approximately $1 \mathrm{~nm}$. On the timescale of months the $\gamma-\mathrm{Fe}_{2} \mathrm{O}_{3}$ layer gets thicker. Annealing in an oxygen atmosphere accelerates this process. The introduction of an even thinner $\mathrm{MgFe}_{2} \mathrm{O}_{4}$ capping layer can prevent the initial oxidation, while caps of $20 \mathrm{~nm}$ of $\mathrm{MgO}$ fully protect the $\mathrm{Fe}_{3} \mathrm{O}_{4}$ thin films. Best results have been achieved by a combination of thin $\mathrm{MgFe}_{2} \mathrm{O}_{4}$ cap and the $\mathrm{MgO}$ cap. While protecting samples with $\mathrm{MgO}$ is not a problem for optical measurements, it poses a problem in electrical measurements, or if the $\mathrm{Fe}_{3} \mathrm{O}_{4}$ is to be used as conductive or spin injecting buffer layer. In this case $\mathrm{MgFe}_{2} \mathrm{O}_{4}$ capping can be used as an alternative, as long as samples are processed within a couple of days after the growth.

The authors would like to acknowledge funding by Science Foundation Ireland under grant number 12/IA/1264. O. Mauit acknowledges support of the Program Bolashak funded by the government of Kazakhstan.

${ }^{1}$ H. Zeng, J. Li, J. P. Liu, Z. L. Wang, and S. Sun, Nature 420, 395 (2002).

${ }^{2}$ R. Hiergeist, W. Andrä, N. Buske, R. Hergt, I. Hilger, U. Richter, and W. Kaiser, J. Magnetism and Magnetic Mater. 201, 420 (1999).

${ }^{3}$ P. A. Miles, W. B. Westphal, and A. Von Hippel, Rev. Mod. Phys. 29, 279 (1957).

${ }^{4}$ S. Lee, A. Fursina, J. T. Mayo, C. T. Yavuz, V. L. Colvin, R. G. Sumesh Sofin, I. V. Shvets, and D. Natelson, Nature Mater. 7, 130 (2008).

${ }^{5}$ C. H. Li, Phys. Rev. 40, 1002 (1932).

${ }^{6}$ L. McGuigan, R. C. Barklie, R. G. S. Sofin, S. K. Arora, and I. V. Shvets, Phys. Rev. B 77, 174424 (2008).

${ }^{7}$ A. Schlegel, S. F. Alvarado, and P. Wachter, J. Phys. C 12, 1157 (1979).

${ }^{8}$ A. J. M. Kuipers and V. A. M. Brabers, Phys. Rev. Lett. 39, 488 (1977).

${ }^{9}$ W. F. J. Fontijn, P. J. van der Zaag, M. A. C. Devillers, V. A. M. Brabers, and R. Metselaar, Phys. Rev. B 56, 5432 (1997).

${ }^{10}$ S. K. Park, T. Ishikawa, and Y. Tokura, Phys. Rev. B 58, 3717 (1998).

${ }^{11}$ W. H. Bragg, Phil. Mag. 30, 305 (1915).

${ }^{12}$ M. S. Senn, J. P. Wright, and J. P. Attfield, Nature 481, 173 (2012).

${ }^{13}$ H.-C. Wu, M. Abid, B. S. Chun, R. Ramos, O. N. Mryasov, and I. V. Shvets, Nano Letters 10, 1132 (2010).

${ }^{14}$ N. Uekawa and K. Kaneko, J. Phys. Chem. B 102, 8719 (1998).

${ }^{15}$ J. P. Hong, S. B. Lee, Y. W. Jung, J. H. Lee, K. S. Yoon, K. W. Kim, C. O. Kim, C. H. Lee, and M. H. Jung, Appl. Phys. Lett. 83, 1590 (2003).

${ }^{16}$ F. Bourgeois, P. Gergaud, H. Renevier, C. Leclere, and G. Feuil- 
let, Journal of Applied Physics 113, 013510 (2013), and references therein.

${ }^{17}$ W. F. J. Fontijn, R. M. Wolf, R. Metselaar, and P. van der Zaag, Thin Solid Films 292, 270 (1997).

${ }^{18}$ W. Eerenstein, T. T. M. Palstra, T. Hibma, and S. Celotto, Phys. Rev. B 66, 201101 (2002).

19 J.-B. Moussy, S. Gota, A. Bataille, M.-J. Guittet, M. GautierSoyer, F. Delille, B. Dieny, F. Ott, T. D. Doan, P. Warin, P. Bayle-Guillemaud, C. Gatel, and E. Snoeck, Phys. Rev. B 70, 174448 (2004).

${ }^{20}$ S. K. Arora, H.-C. Wu, R. J. Choudhary, I. V. Shvets, O. N. Mryasov, H. Yao, and W. Y. Ching, Phys. Rev. B 77, 134443 (2008).

${ }^{21}$ S. Tiwari, D. M. Phase, and R. J. Choudhary, Applied Physics
Letters 93, 234108 (2008)

${ }^{22}$ A. M. Jubb and H. C. Allen, ACS Applied Materials \& Interfaces 2, 2804 (2010).

${ }^{23}$ J. P. Cunniffe, D. E. McNally, M. Liberati, E. Arenholz, C. McGuinness, and J. F. McGilp, phys. stat. sol. (b) 247, 2108 (2010).

${ }^{24} \mathrm{~S}$. Bader, Journal of Magnetism and Magnetic Materials 100, 440 (1991).

${ }^{25}$ K. J. Kim, H. S. Lee, M. H. Lee, and S. H. Lee, J. Appl. Phys. 91, 9974 (2002).

${ }^{26}$ R. Burlakova, I. Edelman, K. Koval, and V. Pavlov, Soviet Physics - Solid State 17, 195 (1975). 